Foro Interno. Anuario de Teoría Política

ISSN: $1578-4576$

http://dx.doi.org/10.5209/rev_FOIN.2015.v16.53889

\title{
Una revisión del realismo maquiaveliano: El problema de las armas propias
}

\author{
Agustín Volco ${ }^{1}$ \\ Recibido: 27 de diciembre de 2014 / Aceptado: 1 de abril de 2015
}

Resumen. La asociación de la enseñanza de Maquiavelo con el consejo de poseer armas propias tiene un carácter casi axiomático en las interpretaciones de su obra. Sin embargo, la aparente simplicidad de esta fórmula supone una lectura poco satisfactoria del texto maquiaveliano. Las recurrentes contradicciones de Maquiavelo sobre el asunto, así como las historias referidas por él, desmienten abiertamente en ciertos casos la eficacia del consejo de poseer armas propias. Tomando como punto de inicio la interrogación sobre esta cuestión, nos proponemos analizar la comprensión maquiaveliana del fundamento del poder (si son efectivamente las armas sin más, o si interviene algún elemento de otro orden), que con el avance de la lectura irá mostrando nuevas dimensiones: su relación con la representación y sus figuras, la importancia de la apariencia y la escena del espectáculo del poder, la cuestión de la legitimidad del poder y el lugar de la religión y del conocimiento filosófico.

Palabras clave: Maquiavelo; armas; poder; religión; filosofía.

\section{[en] A Revision of Machiavellian Realism: The Problem of One's Own Weapons}

\begin{abstract}
The association of Machiavelli's teaching with the advice of possessing one's own weapons has become axiomatic in the interpretation of his work. Nonetheless, the apparent simplicity of this formula implies an inadequate interpretation of Machiavelli's text. His frequent self-contradictory statements on the subject, as well as the stories he tells in his books, deny in certain cases the accuracy of the advice of possessing one's own weapons. We intend to analyze Machiavelli's understanding of the foundations of power (if it relies simply on weapons or if an element of another order intervenes), and the development of our reading will reveal new dimensions such as the relationship with representation and its figures, the importance of appearance and the scene of the spectacle of power, the question of the legitimacy of power, and the place of religion and philosophical knowledge.
\end{abstract}

Keywords: Machiavelli; weapons; power; religion; philosophy.

Cómo citar: Agustín Volco, "Una revisión del realismo maquiaveliano: El problema de las armas propias”: Foro Interno. Anuario de Teoría Política, vol. 16 (2016), pp. 45-66.

Uno de los tópicos más transitados por las interpretaciones de la obra de Nicolás Maquiavelo (1469-1527) es el de la necesidad por parte del príncipe o la república de armas propias. Estas lecturas se apoyan en declaraciones explícitas del propio

1 Universidad de Buenos Aires-CONICET (Argentina).

E-mail: avolco@sociales.uba.ar 
Maquiavelo ${ }^{2}$; la defensa de las armas propias frente a las auxiliares o mercenarias parece uno de los argumentos menos discutibles de la obra maquiaveliana.

Esta interpretación, a su vez, ha apoyado la idea de un Maquiavelo realista, técnico del poder político, que devela la verità effettuale de la cosa política, que libera el análisis político no solo de la moral, sino también de las ilusiones de la imaginación, para comprender científicamente el poder. Esta comprensión científica del poder, asimismo, nos describe a un Maquiavelo dedicado al análisis crudo, aun despiadado, de la política por fuera de toda consideración de otro orden; en suma, que consagraría el análisis de lo político a la realidad de la relaciones de fuerza y no a su imaginación. El fragmento fundamental que da lugar a esta interpretación es el que se encuentra al inicio del capítulo XV, donde se afirma querer ir a la verità effettuale de la cosa política.

Las armas y las armas propias quedarían entonces del lado de la realidad, mientras que la ética, la religión, la moralidad, serían del orden de una imaginación que nublaría el conocimiento de lo político, y que enmascararían aquella realidad que justamente el pensamiento maquiaveliano vendría a desenmascarar (para fundar, así, el conocimiento científico, verdadero, de la política, emancipada ya de sus dependencias de otras esferas de la vida humana). El análisis de lo político se haría él mismo con las armas propias de la razón calculadora atenta a las relaciones de fuerza, y se desprendería de las buenas intenciones de la moral que no serían más que armas de otros.

Como tal vez quede preanunciado en esta descripción, esta lectura de Maquiavelo que asocia el argumento de las armas propias con el de un realismo volcado al análisis crudo de las relaciones de fuerza es la que nosotros pretendemos poner en cuestión y discutir en este trabajo. ¿Por qué? Podemos afirmar, preliminarmente, que consideramos que una lectura en esos términos, si bien encuentra, como hemos mencionado, apoyatura textual, aun en algunas de las frases más célebres de Maquiavelo, no consigue, a nuestro juicio, dar cuenta de la complejidad de la comprensión maquiaveliana de la política y el poder, y pierde de vista algunas de sus sugerencias más importantes, interesantes y, en algunos casos, menos reconocidas de la obra maquiaveliana.

\footnotetext{
"Afirmo, pues, que las armas con las que un príncipe defiende su Estado son o suyas, o mercenarias, o auxiliares o mixtas. Las mercenarias y auxiliares son inútiles y peligrosas, y si alguien mantiene su Estado apoyándose en tropas mercenarias, jamás se hallará estable ni seguro a causa de su desunión, ambición, indisciplina e infidelidad; de su arrogancia con los aliados y cobardía frente a los enemigos; sin temor de Dios, ni lealtad a los hombres, tanto se difiere la caída cuanto se difiere el ataque; en la paz te expolian ellas; en la guerra, los enemigos... Deseo mostrar aún mejor lo pernicioso de tales tropas. Los cabecillas de los mercenarios son hombres excelentes o no: si lo son, no puedes confiar en ellos, pues siempre aspirarán a engrandecerse a sí mismos, ya sea oprimiéndote a ti, su patrón, o a otros, sin echarte cuenta; y si carecen de virtud, normalmente te hacen caer". Nicolás Maquiavelo, El Príncipe, capítulo XII. "Cuántas censuras merecen el príncipe o la república que no tienen ejército propio". Maquiavelo, Discursos sobre la primera década de Tito Livio [en adelante, Discursos], I, XXI. "Cuánta es la diferencia entre un ejército satisfecho que combate por su gloria, y otro malcontento que pelea por la ambición ajena; porque los ejércitos romanos, mandados por los cónsules, casi siempre fueron victoriosos, y por los decenviros siempre vencidos. Este ejemplo es uno de los que demuestran la inutilidad de los soldados mercenarios, los cuales combaten únicamente por el dinero que reciben, motivo insuficiente para hacerles fieles y adictos hasta el punto de dar la vida por la causa que defienden; y si los ejércitos no consideran como propia dicha causa, carecen del valor necesario para resistir a un enemigo algo esforzado". Ibid., I, XLIII. "Peligros a que se exponen los príncipes o repúblicas que se valen de tropas auxiliares o mercenarias"; "Si no hubiera tratado extensamente en otra obra mía de lo inútil que es la milicia mercenaria y auxiliar, y de lo útil que es la propia". Ibid., II, XX. Las traducciones de los textos de Maquiavelo son propias, si bien seguimos generalmente la de Maquiavelo, Obras seleccionadas, Gredos, Madrid, 2011.
} 
Nuestro cuestionamiento de esta lectura (y el paralelo desarrollo de una comprensión de la cuestión de las armas, y de las múltiples dimensiones que se encuentran implicadas en su comprensión) se apoyará en cinco argumentos, que nos darán el hilo del desarrollo del presente trabajo. En primer lugar, sostendremos que existe una paradoja acerca de noción de armas propias: resulta evidente que estas nunca pueden ampliar su fuerza y su alcance, ni mucho menos constituir un gran ejército, sin convertirse en armas de muchos; en segundo lugar, en Maquiavelo la cuestión de la representación, y del modo en que la figura del príncipe aparece frente a los otros resulta, en muchas ocasiones, ser más importante que la fuerza real que cada uno posee; en tercer lugar, la obra maquiaveliana está plagada de ejemplos de hombres que triunfan sin armas propias; en cuarto lugar, muchos de los ejemplos que realizan el elogio de las armas propias resultan engañosos, y una lectura atenta puede revelar un pliegue del argumento inadvertido a una primera lectura; en quinto lugar, el propio Maquiavelo señala la importancia del engaño y, de hecho, la superioridad del engaño por sobre la fuerza a la hora de establecer las relaciones de fuerza ${ }^{3}$. Esta dimensión del poder, considero, abre el discurso a una comprensión del rol de la imaginación en general, y de la religión en particular, que resulta fundamental a la hora de comprender la relación política y los modos de ejercicio del dominio. Comprensión que quedará muy lejos, anticipamos, de aquella que sostiene la interpretación realista del Maquiavelo técnico del poder.

\section{Armas propias}

¿Qué serían las armas propias? En primer lugar, las armas no mercenarias o auxiliares, es decir, las armas que se encuentran bajo el liderazgo de un príncipe y no bajo el liderazgo de otro. Sin embargo, en este sentido, salta a la vista que no hay armas que puedan llamarse con justicia propias en sentido estricto. La propiedad de las mismas involucra inmediatamente la cuestión del régimen político: ejército popular, ejército de los aristócratas, ejército personal de un príncipe. Ya en este primer sentido es posible verificar que la potencia de las armas se juega en una relación, y que, en ese sentido, las armas son siempre ajenas o, en todo caso, se encuentran siempre definidas por una relación con otros que obstruye la posibilidad de la propiedad en el sentido de aquello que puede ser plenamente decidido por el sujeto propietario.

El que obre de otro modo [no ejecutando todas las crueldades de una vez], sea por debilidad o mal consejo, andará siempre necesitado de llevar empuñado el cuchillo; y nunca podrá ampararse en sus súbditos, pues sus renovadas y continuas injusticias les privan de garantías frente a él ${ }^{4}$.

Esta situación de "llevar siempre empuñado el cuchillo" sería la última ratio de las armas propias. En ella se muestra con toda claridad el fracaso de cualquier estrategia de poder, y aun de cualquier estrategia de seguridad personal fundada en

\footnotetext{
Sería insensato no esperar que un autor que habla explícitamente de la superioridad del engaño, y más aún de un engaño que "cuanto más oculto es, más virtuoso es", no utilizara algunos artilugios engañosos en su propia escritura. Maquiavelo, Discursos, II, XIII.

4 Maquiavelo, El Príncipe, VIII, final. Las cursivas en el texto son nuestras.
} 
esta comprensión literal de la idea de las armas propias. Esta reducción al absurdo ilustra bien cómo toda fuerza relevante supone, necesariamente, su constitución en un vínculo político: relación con mercenarios a sueldo, con el pueblo o del pueblo consigo mismo. Asimismo, esta fuerza es siempre relativa a la percepción de la fuerza de los vecinos y potenciales enemigos; en suma, las armas propias no pueden ser nunca estrictamente propias, y suponen en cada una de sus posibilidades una trama más amplia en la que estas cobran significado y se constituyen.

Asimismo, la secuencia I, II-VI de los Discursos muestra que el ejército más poderoso resulta ser el ejército popular democrático de la República Romana, por sobre el modelo aristocrático o el del liderazgo personal del príncipe. Las armas propias parecen ganar eficacia en la medida en que esa propiedad se expande a todo el pueblo: Roma sería superior a Esparta y a Venecia. Sin embargo, la advertencia de Maquiavelo es suficientemente clara: "si quieres un pueblo numeroso y armado para llegar a un gran imperio, lo haces de modo tal que nunca lo podrás manejar después a tu gusto: si lo mantienes pequeño o desarmado para poder manejarlo, si conquistas

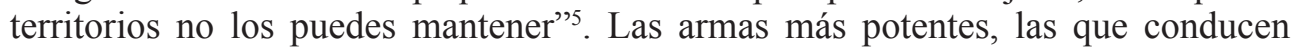
a la mayor gloria, no son fácilmente manejables, requieren la institución de una relación política con un sujeto (el pueblo) que, precisamente, para que despliegue toda su potencia, debe vivir en un régimen de libertad. Y, sin embargo, tampoco podemos decir que el sujeto de las armas propias sea el pueblo sin más, puesto que este depende a su vez de su relación con los líderes políticos para alcanzar cierta relevancia política ${ }^{6}$.

En suma, existe una paradoja en relación con las armas propias: resulta evidente que nunca pueden ampliar su fuerza y su alcance, ni mucho menos constituir un gran ejército, sin convertirse en armas de muchos. A su vez, las armas de muchos solo pueden ser propias mediante el liderazgo político, y este requiere muchas más cosas que acumulación de fuerzas o medición de relaciones de fuerza. La complejidad del vínculo político de constitución de un liderazgo es anterior, y mucho más relevante para pensar la política, que el hecho de poseer armas ${ }^{7}$.

\section{La apariencia del poder y la verità effettuale}

Maquiavelo niega en el célebre fragmento que da inicio al capítulo XV de $E l$ Príncipe la relevancia de un poder trascendente a lo político, ya sea fundado en la

\footnotetext{
Maquiavelo, Discursos, I, VI

"Y es más verdadero que cualquier otra verdad que donde hay hombres y no hay soldados, esto nace por defecto del príncipe, y no por otro defecto, o del sitio, o de naturaleza”. Ibid., I, XXI. Debe darse importancia a esta expresión "mas verdadero que cualquier otra verdad"(es decir, más verdadero que las condiciones naturaleza, por ejemplo) que no vuelve a aparecer en la obra de Maquiavelo. En ella se sostiene como al pasar que, si la milicia es importante, sobre quien pesa la responsabilidad de hacer de los hombres soldados (y sobre quien cae la culpa si fracasa) es sobre el príncipe. Esto es más verdadero que cualquier otra verdad: podríamos decir, más allá de las condiciones del terreno o, fundamentalmente, de la naturaleza de los hombres. Se afirma, considero, en suma, la maleabilidad de los hombres antes que su determinación por una naturaleza.

Los motivos de esto podrían encontrarse a lo largo de toda la obra maquiaveliana: desde el ejército popular que requiere la representación política del pueblo, hasta las alertas que el propio Maquiavelo sugiere acerca del peligro para el líder político de los amigos mucho más que de los enemigos. "Se ve, pues, que todos los conspiradores contra los príncipes han sido personajes o amigos íntimos de aquéllos”. Ibid., III, VI. "Ciriaco dal Borgo, antiguo jefe de la infantería florentina, ha afirmado en mi presencia muchas veces, no haber sido jamás derrotado sino por la caballería de los amigos". Ibid., II, XVI.
} 
virtud moral de los filósofos o en la virtud religiosa del cristianismo. Allí se afirma que: "mi intención es escribir algo útil para quien lo lea, y entonces me ha parecido más conveniente seguir la verdad efectiva (verità effettuale) de la cosa y no su representación imaginaria. Y muchos han imaginado repúblicas y principados que nadie vio nunca y que no existieron en la realidad". Esta frase suele interpretarse como el punto fundacional de la tradición realista del pensamiento político ${ }^{8}$. Sin embargo, aquello que el trabajo de interpretación de la obra maquiaveliana nos va mostrando es, precisamente la dificultad del pensamiento político para acceder a tal verità effettuale: de hecho, el propio Maquiavelo, no nos ofrece una vía clara hacia ella.

Por otro lado, podemos identificar también una dimensión adicional del argumento maquiaveliano que no debería ser soslayada tampoco, en la que se desarrolla una comprensión del poder que no se limita a las relaciones de fuerza, o a lo que suele entenderse como verità effettuale, sino que considera la dimensión de la apariencia como intrínseca a lo político9 ${ }^{9}$ El movimiento del pensamiento inaugurado por

8 Citamos, sin ánimo de exhaustividad, algunas de las interpretaciones más significativas de este fragmento como una declaración de realismo por parte de Maquiavelo. “[En el capítulo XV] Maquiavelo...traza una línea de demarcación firme y clara entre él y sus predecesores 'idealistas', que habían tratado de adaptar y subordinar la teoría política a esquemas teológicos o metafísicos. El escritor se movía a partir de la observación y de la experiencia extraída de la práctica política: sin un fundamento puramente empírico, la penetración de la verdadera naturaleza de la política, la comprensión de las leyes que rigen los fenómenos políticos, le parecían imposibles...es como si él mismo vislumbrara las lejanas consecuencias implícitas en la aplicación del método realista a la esfera del pensamiento político". Felix Gilbert, Machiavelli e il suo tempo, Il Mulino, Bologna, 1964, pp. 109-110. "La línea de demarcación entre el propio modo de pensar y el de los predecesores es clara e inequívoca. Maquiavelo rompe con toda teoría política fundada sobre presupuestos teológicos y metafísicos: a esos esquemas contrapone lo real de la experiencia y de la historia; a la imaginación de la cosa, la realidad efectiva". Ugo Dotti, Niccolò Machiavelli: la fenomenologia del potere, Feltrinelli, Milano, 1979, p. 87. De acuerdo con Olschki, Maquiavelo hizo de la política "un sistema de reglas universales" ("a system of universal rules"), esto es, "de leyes intrínsecas a descubrir mediante un método de razonamiento inductivo" ("of intrinsic laws to be discovered by an inductive method of thinking"). Leonardo Olschki, Machiavelli the Scientist, Gillick Press, Berkeley, 1945. Asimismo, según Butterfield, "la esencia de su enseñanza era la promoción de una técnica de gobierno más científica". ("The essence of his teaching was the promotion of a more scientific statecraft"). Herbert Butterfield, The Statecraft of Machiavelli, Collier, New York, 1962, p. 16. Mindle, en cambio, pone en cuestión el realismo de Maquiavelo, pero no pone en cuestión que la intención de Maquiavelo fuera ser realista. Por ello afirma que "el sello distintivo de la ciencia política de Maquiavelo es su realismo. ¿Qué otra expresión podría describir la enseñanza de un autor determinado a escribir algo útil incluso bajo el riesgo de aparecer presuntuoso, por no hablar del propósito de una obra (El Príncipe) cuyo propósito explícito es el de exponer la verdad efectiva, hasta entonces escondida al género humano detrás del idealismo corporizado en toda la ciencia política previa?". ("The hallmark of Machiavelli's political science is its realism. What other expression could adequately describe the teaching of an author determined to write something useful even at the risk of appearing presumptuous, let alone that of a work [The Prince] whose express purpose is to set out 'the effectual truth' heretofore hidden from mankind behind the idealism embodied in all previous political science?"). Grant B. Mindle, "Machiavelli's Realism": The Review of Politics, vol. 47, n. ${ }^{\circ} 2$ (1985), p. 212. Skinner sostiene, a su vez, que "no hay dudas, sin embargo, de que Maquiavelo pone un énfasis extraordinariamente fuerte en el rol de la fuerza en la dirección del gobierno". ("There is no doubt, however, that Machiavelli places an exceptionally strong emphasis on the role of sheer force in the conduct of government"). Quentin Skinner, The Foundations of Modern Political Thought, Cambridge University Press, Cambridge, 1978, p. 130.

9 Ha sido Claude Lefort quien ha desarrollado con mayor intensidad una lectura de Maquiavelo sostenida en el carácter constitutivo de la dimensión de la apariencia para la comprensión de la política maquiaveliana. Claude Lefort, Le travail de l'œuvre Machiavel, Gallimard, Paris, 1972, pp. 399-432. Pierre Manent, siguiendo en esto a Lefort, afirma que "los fenómenos de la potencia son fenómenos inevitables y esenciales, pero, de una cierta manera, fenómenos secundarios". ("Les phénomènes de la puissance son des phénomènes inévitables et essentiels mais, d'une certaine manière, des phénomènes seconds"). Pierre Manent, Naissances de la politique moderne: Machiavel, Hobbes, Rousseau, Payot, Paris, 1977, p. 35. 
Maquiavelo entonces no es simplemente un rechazo de la imaginación para abocar la reflexión a la realidad, sino una afirmación del carácter necesariamente imaginativo de la realidad política ${ }^{10}$. Insistamos: no olvida la imaginación para llevarnos a la realidad, sino que destituye a la realidad misma de su carácter de certeza con la misma intensidad con la que destituye la certeza de los valores morales.

Entonces, ¿cuál es la verità effettuale? No se nos responde directamente a esa pregunta en toda la obra de Maquiavelo. Se ha interpretado el sentido de esta verità effettuale como una suerte de rudimentario empirismo, apoyado en la "larga experiencia de las cosas modernas y en una continua lección de las antiguas"11. Sin embargo, una minuciosa atención al texto maquiaveliano nos muestra, como veremos más abajo, que el recurso a las historias, tanto antiguas como modernas, desempeñan un rol muy distinto del de servir de ilustración, o de prueba de las máximas políticas expresadas. Las historias, de hecho, muchas veces contradicen las máximas que, se supone, deberían ilustrar. Corroborar esta irregularidad del discurso maquiaveliano nos exigirá dar cuenta en el trabajo interpretativo del sentido de estas discordancias y, a partir de ello, del contenido mismo de la enseñanza del propio Maquiavelo. Como hemos señalado, los ejemplos históricos que hemos revisado nos muestran que el recurso a las historias (no menos que el recurso a las autoridades de la Biblia o la filosofía clásica) resulta engañoso: deberían bastarnos para dar cuenta de ello las contradicciones en las referencias a algunos de los personajes históricos más importantes que Maquiavelo evoca en su escritura: Moisés ${ }^{12}$, Rómulo (771-717 a. e. c. $)^{13}$, César Borgia (1472-1507) $)^{14}$, Aníbal (247-183 a. e. c. $)^{15}$, Agátocles (361-289 a. e. c. $)^{16}$ o Jenofonte (ca. 431-354 a. e. c. $)^{17}$. Para cada uno de estos las referencias que hace Maquiavelo resultan contradictorias, desconcertantes, no solo en lo que refiere a las cualidades de sus personajes, sino en relación con los problemas fundamentales que a través de estos personajes son tratados: la virtud, la crueldad, la fortuna, el bien y el mal, de la naturaleza humana, pero también el fundamento del poder político, y el fundamento del saber acerca de la política.

Podemos detenernos entonces para obtener una indicación en la palabra effetuale, que nos permite interpretar esa expresión en el sentido de aquello que se produce en el juego de los efectos, y por ello mismo, en el campo de una relación, de aquello que en la relación de un hombre con otro u otros produce un efecto. Si esta lectura se sostiene, lo real no nos provee el suelo firme de la certeza, sino el panorama de

10 Lars Vissing, Machiavel et la politique de l'apparence, Presses Universitaires de France, Paris, 1986.

11 Maquiavelo, El Príncipe, Dedicatoria.

12 Admirable por su capacidad de hablar con Dios y fundador glorioso (Maquiavelo, El Príncipe, VI), o un hombre que "cometió infinitos asesinatos" (Maquiavelo, Discursos, III, XXX).

13 Fratricida o fundador glorioso. Ibid., I, IX; ibid., I, XIX.

14 Ejemplo a ser seguido en el capítulo XIII de El Príncipe, en el capítulo VII se concluye afirmando que fracasó por un error propio: "erró el duque en esta elección, y ésta fue la razón última de su ruina". Maquiavelo, $E l$ Príncipe, VII.

15 Cruel y extraordinario líder político. Y, si seguimos la sugerencia de El Príncipe, XVII, extraordinario líder político porque supo ser "prudentemente cruel".

16 "Si consideramos la virtud de Agátocles al enfrentar los peligros y salir de ellos, y también su grandeza de ánimo al soportar y superar las adversidades, no vemos motivo para que sea considerado inferior a cualquier otro nobilísimo capitán. Sin embargo, su feroz crueldad, su inhumanidad acompañada de infinitas maldades, no permiten que se le celebre entre los hombres más eminentes". Ibid., VIII. En este caso, la contradicción entre su virtud y su crueldad se presenta en un mismo párrafo.

17 Maestro del engaño (Maquiavelo, Discursos, II, XIII), maestro de virtudes principescas (Maquiavelo, El Príncipe, XIV). 
una serie de relaciones siempre sujeta necesariamente al cambio, y se constituye en la trama misma de las relaciones entre los hombres. Ese juego de apariencias, entramado de efectos de las relaciones entre los hombres, no encuentra su verdad en ninguna esencia que subyace o trasciende al orden mismo de las apariencias.

Hay también en el caso de las referencias a los personajes mencionados una verità effettuale: es decir, una verdad que se comunica en cierta medida a través de un texto que se juega en los efectos, en el desconcierto que produce en algunos lectores la distancia entre unas proposiciones y otras, o en la incongruencia de la imagen que se nos ofrece de algunos personajes, en la perplejidad que genera en el lector, y en la incertidumbre que en estos juegos de referencias se produce respecto de las categorías tradicionales del pensamiento político. Luego de leer estos pasajes con cierto cuidado, el lector queda desconcertado sobre la relación entre crueldad y buen gobierno, o sobre la posibilidad de que "sea lícito decir bien del mal"18, o sobre las cualidades de algunos de los personajes políticos más eminentes de la tradición. Lo que se nos ofrece en estos juegos de referencias a quien pretenda seguirlos es una imagen de estos personajes y estos conceptos irreductible a la simplicidad de una imagen unívoca o una máxima de fácil comprensión, a una comprensión lineal susceptible de una definición clara y distinta; difícilmente pueda encontrarse en la obra maquiaveliana una afirmación que no pueda ser contradicha con otra. Algo de esta verdad se juega entonces, también, en la relación entre escritor y lector, en los efectos de conmoción de algunos puntos de apoyo de las certezas de la tradición que el texto produce.

Lo real político, la veritá effetuale, está constituido entonces por una trama que es ella misma imaginativa. El poder, volvamos a eso, no se juega nunca en la realidad de las armas, puesto que no existe tal cosa: la relación política del pueblo con la ciudad (ya sea en un principado o en una república) es una fuente de poder mucho más importante, y provee una seguridad mucho mayor que la seguridad imaginaria de las armas propias ${ }^{19}$. El poder se encuentra siempre ligado a una imagen y se funda en una red de relaciones que se instituye sin referencia a un orden fijo e inmutable.

Se trata de la cuestión de la apariencia: como dijimos, el príncipe no tiene armas propias, sino que se apoya en el pueblo ${ }^{20}$, en los grandes, o en mercenarios (y cada una de estas alternativas, a su vez, abre el campo de una cierta política, y un cierto horizonte para su aventura). Maquiavelo se inclina, como sabemos (aunque no sin excepciones dictadas por la ocasión) por la alternativa popular. Pero el príncipe no es el pueblo ni puede identificarse con él: si lo hiciera, desaparecería inmediatamente la necesidad de su misma existencia política (el régimen de un príncipe apoyado en el pueblo no es lo mismo que el de un gobierno popular). Por lo tanto, las armas propias son en realidad las armas de otro: las armas del príncipe son las armas del pueblo en la medida en que este reconozca al príncipe como legítimo. Todo el problema se juega en la dimensión de la apariencia y la representación, es decir, en el modo en que se establece la relación del príncipe con el pueblo. Si en algún sentido las armas

18 Maquiavelo, El Príncipe, VIII.

19 Lo mismo puede afirmarse de las murallas. Si el argumento del capítulo X de El Príncipe parece hacer un elogio de las murallas, mientras avanza el capítulo el peso del argumento se desplaza cada vez más a la relación del príncipe con el pueblo (y fundamentalmente a la capacidad del príncipe de no hacerse odiar por el pueblo) como principio fundamental de la seguridad del príncipe.

20 Maquiavelo, Discursos, I, LII, por ejemplo, se habla de "favorecer al pueblo" como un "arma" en dos ocasiones. 
del príncipe son propias, es en el de obtener un reconocimiento por parte del pueblo de la legitimidad de su liderazgo y su autoridad.

La constitución del poder se revela como una relación ordenada en torno a una apariencia: la fama y la reputación no deben ser comprendidas, en este sentido, como aquello que oculta, disimula, embellece o da pompa a lo real, sino como aquello que constituye lo real político; la realidad política no es sino esa trama de apariencias que no pueden referir a una esencia que las ordena y les da fundamento. Si el poder se constituye en una relación, lo fundamental no será ya aquello que una de las partes es (es decir, cuáles virtudes morales posee, o no, como sancionaría toda la tradición de los espejos para príncipes), ni aquello que posee (dinero ${ }^{21}$, armas) sino aquello que aparece, $\mathrm{y}$, fundamentalmente, aquello que del príncipe aparece frente al pueblo.

La presentación que Maquiavelo hace de Agátocles nos permite iluminar esta dimensión de la reputación como elemento constitutivo del poder. Justamente lo que no logró Agátocles, pese a no hacer nada distinto que Borgia o Francesco Sforza (1401-1466), fue quitarse la reputación de tirano, "conquista el poder pero no la gloria"22. Sin embargo, al presentarse la equivalencia entre su figura, criminal, y la de Borgia, príncipe "a ser imitado" 23 , se nos pone de manifiesto precisamente el carácter no necesariamente ligado a la acción o a la virtud principesca de su reputación. Desde el punto de vista de las acciones, Agátocles no se distingue de Borgia, desde el punto de vista de la reputación, aparecen nítidamente diferenciados: "Pero no se puede llamar virtud asesinar a los conciudadanos, traicionar a los amigos y mostrarse sin lealtad, sin piedad, sin consciencia, sin un ideal moral: estos modos pueden hacer adquirir poder, pero no gloria" ${ }^{24}$.

Ahora bien, como veremos, esta dimensión de la apariencia resulta para Maquiavelo fundamental, y es en el contexto de esta forma apariencial del poder que se puede interpretar la importancia de la religión como instrumento de poder. Esta cuestión se vincula estrechamente con la del realismo o empirismo maquiaveliano. Si la comprensión maquiaveliana del poder no abandona la dimensión de la imaginación para abocarse a la realidad, sino que propone una comprensión de la realidad como ella misma imaginativa, la crítica de la religión no podrá ser, como se ha interpretado frecuentemente, la de formular un engaño que oculta la realidad, sino que los términos de la disputa deberán ser presentados de modo diverso. Podríamos decir que Maquiavelo no opone a la falsa certidumbre de la religión la verdadera certidumbre de la ciencia o la realidad, sino la verdadera incertidumbre de los asuntos políticos.

\footnotetext{
Ibid., II, X.

Maquiavelo, El Príncipe, VIII.

Ibid.,VII.

24 Algo similar puede decirse de la progresión de los primeros tres reyes de Roma y la importancia de la reputación. En Discursos, I, XIX, Maquiavelo, luego de mencionar a un primer rey de Roma feroz (Rómulo) y un segundo pacífico (Numa), refiere que si el tercero hubiera sido "incapaz de darle [a Roma] su reputación con las armas, nunca más hubiera podido hacer pie". Es decir, el tercer rey consiguió no solo ganar las armas, sino también la reputación; sin esto, Roma no hubiera podido "obtener los resultados que obtuvo" (fare quegli effetti ch'ella fece). La grandeza de Roma no fue la consecuencia de la milicia, sino de aquello que la milicia supone: un orden y un liderazgo, y, por sobre todas las cosas, una maestría en el manejo de algo que no puede ser separado de las armas, que es la reputación. El poderío militar se mide siempre en la relación con los potenciales enemigos y, más importante aún, en relación con el modo en que el enemigo percibe el propio poderío, y en modo en que se percibe el poderío del enemigo. La reputación, entonces, resulta fundamental para la institución del liderazgo político tanto en la relación interna con el pueblo, como en la relación externa con los enemigos.
} 
Sobre esta forma de la apariencia establecida en la dinámica incierta de una relación se puede producir incluso una inversión de la relación entre armado y desarmado, entre poderoso e impotente. Es sobre esta matriz del poder entendido como relación ordenada en torno a una apariencia que Maquiavelo comprenderá la cuestión de la religión. Como veremos, muchos de los ejemplos más significativos a la hora de pensar la cuestión de las armas involucran, de un modo u otro, la cuestión del poder religioso, y más precisamente, la del enigma de un poder desarmado, cuya autoridad proviene y se funda en un principio invisible.

\section{Baglioni}

La historia referida en el capítulo XXVII del primer libro de los Discursos nos ilustrará con mayor precisión que cualquier otra acerca de la importancia de la apariencia a la hora de instituir el poder, y de la instrumentalización que la religión puede hacer de esa dimensión necesariamente apariencial del poder. Allí se refiere a una campaña del Papa Julio II (1443-1513) quien quería quitar Perugia al tirano Giovampagolo Baglioni (1470-1520):

Al llegar [Julio II] junto a Perugia con esta determinación de todos conocida, sin esperar el ejército que le seguía, entró en ella desarmado, a pesar de estar alli Giovampagolo con bastantes tropas que había reunido para defenderse. La impaciente energía [furore] con que el papa gobernaba todas las cosas le hizo ponerse con su pequeña escolta en manos de su enemigo, a quien se llevó consigo, nombrando un gobernador de la ciudad en nombre de la Iglesia ${ }^{25}$.

En este episodio se muestra la prevalencia de la "temeridad" del Papa ${ }^{26}$, por sobre la superioridad militar de Baglioni. Una vez presentada la cuestión, Maquiavelo se muestra sorprendido de que este no aprovechara la ocasión para "adquirir perpetua fama apoderándose, por un golpe de mano, de su enemigo"27, dado que no parece ser una persona restringida por la moralidad tradicional, por la benevolencia o los escrúpulos, y que "ningún sentimiento de piadoso respeto cabía en hombre tan malvado [Baglioni], que abusaba de su hermana y había asesinado, para reinar, a sus primos y sobrinos" 28 .

Maquiavelo reprocha a Baglioni, "que no se avergonzaba de ser públicamente incestuoso y parricida" 29 (podemos notar cómo va in crescendo la abyección moral de Baglioni en cada descripción), no precisamente su inmoralidad, sino el haberse abstenido de cometer un homicidio que parece mucho menos grave, casi insignificante, frente a las maldades ya cometidas, y que, de hecho, le acarrearía una gloria que ninguno de los otros pecados le habría dado:

25 Ibid., I, XXVII. Las cursivas en el texto son nuestras.

26 Recordemos que el propio Maquiavelo declara temer ser tomado por "presuntuoso y temerario" en El Príncipe, XI.

27 Maquiavelo, Discursos, I, XXVII.

28 Ibidem.

29 Ibidem. 
No supo, o mejor dicho, no se atrevió, cuando tenía justo motivo para ello, a realizar una empresa capaz de producir general admiración, dejando de sí eterna memoria, por ser el primero que demostrara a los prelados cuán poco dignos de estimación son los que viven y reinan como ellos, y por ejecutar un acto cuya grandeza habría superado a la infamia y los peligros que llevara consigo $0^{30}$.

Aquello que reprocha Maquiavelo a Baglioni, entonces, parece ser su incapacidad para despojarse completamente de la moralidad, es decir, el hecho de, aun siendo capaz de quebrar el tabú del parricidio y el incesto, resultar incapaz de sustraerse al encanto del aura del poder. A diferencia del Papa, Baglioni no tiene la temeridad para cometer un asesinato honorable. En suma, su incapacidad, que es la de muchos hombres, de "ser honorablemente malos o perfectamente buenos", y de no reconocer "cuando una maldad tiene en sí misma grandeza"31, es la que le impide alcanzar la gloria.

La diferencia entre las violaciones sistemáticas de la moralidad más elemental que Baglioni practica, y aquellas que es incapaz de cometer, radica en que los vicios morales de Baglioni eran privados. Ello no le permitió superar el encanto público que sostenía el poder del Papa, cuyo fundamento era el mismo. Si los vicios privados refieren a la naturaleza del hombre, los vicios políticos entran en la dimensión de la apariencia. Baglioni, cometiendo ese homicidio (que es incapaz de ver como el simple asesinato de un hombre, y sigue considerándolo como un delito de lesa majestad, porque sigue creyendo en la majestad del poder) podría haber sido "el primero que demostrara a los prelados cuán poco dignos de estimación son los que viven y reinan como ellos" ${ }^{\prime 2}$. Sin embargo, no lo hace: Maquiavelo hace sentir al lector lo fácil que sería asesinar al Papa, y al mismo tiempo, hace sensible mediante esa imagen el poder de la representación ${ }^{33}$.

Baglioni no comete un asesinato más noble ${ }^{34}$ y más sencillo que todos aquellos que sí cometió: un hombre como el Papa, desarmado, pero temerario y conocedor de la gramática del poder, tanto en su dimensión visible como invisible, puede vencer contra un tirano armado sin restricción moral alguna. En síntesis, el episodio de

30 Ibidem. Las cursivas son nuestras.

31 Ibidem.

32 Ibidem.

33 Al afirmar que el poder depende de su representación no queremos decir que la cuestión de la moral sea indiferente, o que la política se emancipa de la moral. Un aspecto fundamental de la apariencia del poder es, precisamente, la apariencia de moralidad. De lo que se trata es de comprender el impacto doble de la negación de fundamento de verdad incuestionado de la moralidad, y de la necesidad de una cierta moralidad para dar forma y estabilidad a un orden. Maquiavelo, entonces, pone en cuestión el carácter de verità de esa aspiración a la moralidad, no solo negando la posibilidad de conocer, o dar por cierto un catálogo de virtudes, sino más radicalmente, la necesidad de reconocer su superioridad por sobre las virtudes que pueden ser cultivadas en este mundo, en este tiempo. No tenemos prueba (más que una revelación dudosa, o una enseñanza filosófica errada e imaginativa) de la superioridad de la virtud. Esto revela, entonces, tanto la importancia de las distinciones morales para la política, como la importancia de aquello que se encuentra más allá de las distinciones morales. Podríamos decir: la virtù maquiaveliana es, entre otras cosas, saber presentar al pueblo la apariencia de virtud en sentido clásico, al mismo tiempo que se comprende que la realidad del poder no se deriva de la obediencia a las reglas de la virtud clásica. Sobre el tratamiento maquiaveliano de las virtudes clásicas, véase Felix Gilbert, “On Machiavelli's Idea of Virtu”: Renaissance News, vol. IV, n. 4 (1951), pp. 53-55; Harvey C. Mansfield, Machiavelli's virtue, University of Chicago Press, Chicago, 1996; Clifford Orwin, "Machiavelli's Unchristian Charity": The American Political Science Review, vol. 72, n. ${ }^{\circ} 4$ (1978), pp. 1217-1228.

34 Vale la pena detenerse en el hecho de que a esta altura del argumento ya no llama la atención razonar acerca de "asesinatos nobles". 
Baglioni, nos parece, ilustra con claridad una comprensión del poder que no se reduce a las armas, y mucho menos a las armas propias; o, al menos, como veremos, debería servir para expandir la comprensión de las armas en la obra maquiaveliana.

\section{Las armas, la temeridad y la reputación}

El ejemplo de Borgia, referido en los capítulos VII y XIII de El Príncipe, nos muestra justamente la importancia de la capacidad del líder de pasar de las armas auxiliares a las mercenarias, y de estas a las propias:

Nunca dudaré de poner como ejemplo a Cesar Borgia y sus acciones. Este duque entró en Romaña con las tropas auxiliares integradas solo por franceses, y con ellas tomó Ímola y Forlì, pero esas tropas no le parecieron seguras y recurrió a las mercenarias, considerando que eran menos peligrosas. Así tomó a sueldo a los Orsini y los Vitelli. Sin embargo, después, al controlarlas, encontró que eran sospechosas, desleales y peligrosas, y entonces las liquidó y volvió a sus fuerzas $\operatorname{propias}^{35}$.

La capacidad de adquirir las armas resulta más relevante que la de poseerlas. Ciertamente la virtud de Borgia estuvo en su capacidad para hacerse con un ejército bajo su mando, y su recorrido ascendente ${ }^{36}$ muestra cómo, a partir de un ejército que no le pertenece, logra un ejército propio.

Se puede ver fácilmente la diferencia entre las dos armas, en cuanto se considere qué diferencia hubo entre la reputación del duque cuando tenía solo a los franceses, cuando tenía a los Orsini y los Vitelli, y cuando se quedó con sus propios soldados, apoyándose en sí mismo. Y de este modo su reputación creció y nunca fue estimado tanto hasta que todos vieron que él era el dueño absoluto de sus tropas ${ }^{37}$.

Ahora bien, a la hora de sacar una conclusión del periplo de Borgia, Maquiavelo no habla una sola vez de su poder como si se tratara de una dimensión objetiva, sino que se refiere recurrentemente a su reputación, es decir, al modo en que fue considerado por los demás, a aquello que "todos vieron". Para ver la diferencia entre un tipo de armas y otras lo que resulta definitorio es la reputación que Borgia conquista, y el hecho de que "todos vieron" que era dueño absoluto de sus tropas.

35 Maquiavelo, El Príncipe, VII y XIII.

36 Maquiavelo atribuye el fracaso de Borgia en una ocasión a la "malignidad de la fortuna", y en otra, a un "error" suyo que "fue la razón de su ruina definitiva". Maquiavelo, El Príncipe, VII, final. Es decir, en un caso se atribuye el fracaso a la fortuna, en el otro se revela que esa "falta de fortuna" en realidad no era sino falta de virtud. En suma, ya no resulta tan creíble la afirmación anterior de Maquiavelo "nunca dudaré de poner como ejemplo a César Borgia y sus acciones". El único personaje que sufre una "enorme y continua malignidad de fortuna" en El Príncipe además de Borgia es el propio Maquiavelo, tal como se afirma en la epístola dedicatoria. Maquiavelo guarda silencio sobre su propia virtud. Véase Nathan Tarcov, "Machiavelli in The Prince", en Thomas L. Pangle y J. Harvey Lomax (eds.), Political Philosophy Cross-Examined: Perennial Challenges to the Philosophic Life, Palgrave Macmillan, New York, 2013, pp. 101-118.

37 Maquiavelo, El Príncipe, XIII. Cursivas nuestras. 
En el capítulo VII se refiere con algo más de extensión la acción del propio Borgia en la Romaña, que nos permite profundizar aún más el tema de la relación del poder con la apariencia.

César Borgia manda con plenos poderes a un servidor suyo, Ramiro de Orco (1452-1502), a quien precedía la fama de cruel y expeditivo, a actuar en la Romaña para pacificarla, cosa que Ramiro realiza, unificando aquel territorio y ganando gran reputación. Una vez conquistado y pacificado el territorio, Borgia decide "implantar un tribunal civil...presidido por un hombre excelente" 38 , y mostrar que si se había cometido alguna crueldad, esta no provenía de él, sino de "la áspera naturaleza del ministro" 39 . Para purgar los ánimos de aquellos pueblos y ganárselos completamente, a la primera ocasión que se le presenta, lo ejecuta espectacularmente y lo expone partido en dos en la plaza de Cesena con un trozo de madera y un cuchillo ensangrentado al costado. Borgia ejerce, así, un acto de crueldad con quien fue cruel que produce el efecto de la justicia ${ }^{40}$. Y obtiene, de este modo, una reputación de hombre justo ${ }^{41}$ que deja al pueblo, gracias a la ferocidad del espectáculo, soddisfatti e stupidi.

Si la verdad es la verità effettuale, es decir, aquello que se establece como verdadero mediante los efectos que produce, en este caso, esta verità no se juega en la relación con la moralidad o inmoralidad de las acciones, ni con la naturaleza o el carácter de Borgia, sino con los efectos que produce: dejar satisfecho y estupefacto al pueblo, pacificada la Romaña, y su reputación de hombre justo intacta, sin haberse privado de usar los medios necesarios (es decir, la crueldad administrada prudentemente) para lograrlo. Esta legitimidad conquistada por Borgia no guarda relación con la dimensión del ser de Borgia (su naturaleza o carácter), sino que se juega plenamente en la modalidad que asume su aparecer frente al pueblo. De hecho, en cierto modo, se puede decir que la mayor prueba de la indiferencia de la acción política frente a la cuestión de la posesión de las virtudes morales es, precisamente, el hecho de que el príncipe puede incluso poseer aquellas virtudes que aparenta ${ }^{42}$.

Borgia merece el elogio de Maquiavelo precisamente por su capacidad para montar una escena: actúa con la brutalidad necesaria para pacificar un territorio (por la mano de un subordinado), y al mismo tiempo conserva el prestigio y la fama de hombre justo. Este cultivo de la duplicidad resulta fundamental para la conservación del poder. En este sentido, es preciso conservar la carga de ambigüedad del argumento: para Maquiavelo, tanto el gobierno de la pura piedad como el de la pura crueldad son imposibles. Paradójicamente, se suele enfatizar en la interpretación de estos pasajes la crueldad de Borgia mucho más que los cuidados que pone para aparecer como el fundador de la justicia, y proveer una vía de expiación y castigo para el

38 Ibid., VII.

39 Ibidem.

40 Orwin sostiene que este pasaje sugiere una corrección de la doctrina aristotélica de la virtud como justo medio: aquí el justo medio que daría prueba de virtud sería el que se encuentra entre el exceso de crueldad y la falta de crueldad, es decir, la crueldad, sin más. Orwin, "Machiavelli’s Unchristian Charity”, p. 1224.

${ }^{41}$ Al tiempo que capaz de ser cruel, y de pacificar un territorio y una población: la bondad de quien aparece como capaz de ser cruel es mucho más valorada que la de quien no muestra esa posibilidad.

42 Esto no significa, valga decir, que la dimensión del ser sea indiferente al pensamiento, sino simplemente que el saber no asume poseer un acceso privilegiado a la dimensión del ser y que, por lo tanto, en política (y no solo) resulta más cercano a la verdad la asunción de la imposibilidad de probar un saber definitivo acerca de lo justo y lo injusto, lo bueno y lo malo, que la asunción de una posición de saber-poder capaz de dar una palabra definitiva sobre lo que está bien y lo que está mal. 
odio que la crueldad suscita. Aquello que ilumina este pasaje es, a nuestro juicio, que ambas cosas (crueldad y fama de justicia) son necesarias para el gobierno, pero incompatibles para la moralidad convencional y para la percepción del pueblo.

Cuando se vuelve sobre Borgia en el capítulo XVII se comienza reasegurando el saber convencional: un príncipe debe desear ser considerado piadoso y no cruel. Sin embargo, inmediatamente advierte que el príncipe debe cuidarse del mal uso de la piedad y provee un ejemplo de buen uso de la crueldad: Borgia era considerado cruel, pero une la Romaña en "paz y fe" dice Maquiavelo, se verá que Borgia fue "más piadoso que el pueblo florentino, que por huir del nombre de cruel, dejó que se destruyera Pistoia"44. Poquísimos ejemplos de crueldad que impongan paz y fe evitarán muchos más males que el exceso de piedad. El buen uso de las virtudes y los vicios resulta mucho más importante que las cualidades intrínsecas del actor político; y la capacidad de comprender la escena de aparición de la imagen del príncipe frente al pueblo y la lógica que la preside se revela, más allá de la virtud y el vicio, como un rasgo esencial de virtud política.

Si el capítulo comienza reproduciendo la percepción convencional acerca de la superioridad de la piedad por sobre la crueldad, en pocas líneas descubrimos no ya una inversión que haría a la crueldad superior a la piedad, sino una transformación más profunda e inquietante: frente a la prueba de la necesidad, la crueldad puede ser verdadera piedad, mientras que la excesiva piedad puede resultar en crueldad.

Esta referencia doble a Borgia nos permite comprender con mayor profundidad la importancia de la representación y de la espectacularización del poder: el poder no solo se instituye en relación con el pueblo, esta relación está sujeta a la estupefacción, y esta permite a un hombre como Borgia cometer crueldades y pasar por un hombre justo mediante el arte de la expiación del mal en el espectáculo de la justicia ${ }^{45}$. Si el Borgia de Maquiavelo tuvo virtù, fue, entre otras cosas, porque supo comprender la verità effettuale tal como Maquiavelo la comprende.

\section{Triunfar sin armas propias}

Ahora bien, si el caso de Borgia nos provee un ejemplo de virtud sostenido en su capacidad para comenzar sin armas y adquirir armas propias, podemos encontrar también muchos ejemplos en los que Maquiavelo sugiere que es posible, directamente, triunfar sin armas propias. Estos ejemplos son, intentaremos sostener, mucho más relevantes para la enseñanza política maquiaveliana que aquellos en los que se habla

43 Maquiavelo, El Príncipe, XVII.

44 Ibidem. Comentando estos pasajes, Merleau-Ponty observa la inquietante reversibilidad de virtud y vicio: "el político duro ama a los hombres y a la libertad más verdaderamente que el humanista declarado". Es decir, está dispuesto a actuar inmoralmente con tal de "pacificar la Romaña", y con ello, proveer las condiciones para toda vida civil. Maurice Merleau-Ponty, "Note sur Machiavel": Les Temps Modernes V, n. 48 (1949), pp. $557-$ 593. Véase sobre este tema también Eduardo Rinesi, Política y tragedia: Hamlet entre Hobbes y Maquiavelo, Ediciones Colihue, Buenos Aires, 2003, pp. 34-42.

45 La prosa de Maquiavelo abunda en imágenes que dejan "estupefacto y satisfecho" al lector. No podemos dejar de considerar la posibilidad de que el propio Maquiavelo (al igual que su otra víctima de la "malignidad de la fortuna") pretenda utilizar este mismo artilugio (impactar y hacer pasar inadvertido por el impacto de alguna frase o imagen chocante una afirmación que, por algún motivo, prefiera hacer de manera indirecta o velada). Véase, por ejemplo, en el cap. XVIII de El Príncipe la referencia a Quirón. 
de la importancia de poseer armas propias: tomaremos los de David (ca. 1040-966 a. e. c.) y Girolamo Savonarola (1452-1498).

En el capítulo XIII de El Príncipe se nos dice que no se quería salir de los ejemplos italianos y cercanos, pero tampoco se quiere dejar de lado a Hierón de Siracusa (ca. 306-215 a. e. c.). Hierón abandona la tropa mercenaria porque "estaba hecho a la manera de los italianos nuestros; y como le pareció que no podía ni mantenerlos ni abandonarlos, los hizo cortar a todos en pedazos; y luego hizo la guerra con sus propias armas y no con las ajenas" ${ }^{\prime 4}$. Esta cita parece dar cuenta de la necesidad de las armas propias con claridad indudable. Inmediatamente después se cita el Antiguo Testamento ${ }^{47}$ :

Quiero también traer a la memoria una figura del Viejo Testamento relacionada con este tema. David se ofreció a Saul para combatir a Goliat, provocador filisteo. El rey, para infundirle ánimo, le dio sus propias armas pero, en cuanto David las tomó, también las rechazó, diciendo que con ellas no podía valerse por sí mismo y que prefería enfrentar al enemigo con su honda y su cuchillo. En fin, las armas de los otros se te caen de los hombros, te pesan demasiado o te aprietan ${ }^{48}$.

Ambas citas se ofrecen como explicación de la cuestión de las armas propias. Sin embargo, no puede pasarse por alto que el ejemplo de David es uno de los más célebres ejemplos de un triunfo en el que las armas estaban del lado de quien finalmente pierde en la batalla: Goliat. Maquiavelo, nos parece, genera una perplejidad deliberada al hablar del tema ${ }^{49}$, que tiende a poner en cuestión, aunque no diciéndolo abiertamente, la idea de que las armas propias son el principio fundamental de la política. Si en el primer ejemplo se afirma con brutalidad y espectacularmente la necesidad de armas propias mediante el ejemplo de Hierón, esta impresión, tal vez, pueda hacer pasar por alto el hecho de que en la única cita bíblica de todo el texto se refiere una historia que parece sugerir exactamente lo contrario.

Si esta discordancia no fuera suficiente para llamar la atención, descubrimos asimismo que Maquiavelo altera la cita bíblica, poniendo un cuchillo en manos de David. En el texto bíblico no solo no se menciona este cuchillo, sino que se niega explícitamente que tuviera una espada: en el Libro I de Samuel al que se refiere Maquiavelo se afirma que "así venció David al filisteo con honda y piedra; e hirió al filisteo y lo mató, sin tener espada en su mano" 50 . Esta modificación llama la atención, y muestra que Maquiavelo hace a David más armado de lo que realmente estaba según el relato bíblico, en el que se quiere justificar la importancia de las

46 Hierón se enfrenta con una tropa mercenaria "hecha a la manera de los italianos nuestros", pero hace con ella exactamente aquello que ninguno de sus contemporáneos se atreve a hacer: cortar a todos en pedazos. Aun el temerario Maquiavelo pone esas acciones y el consejo que de ellas se deriva en una figura lejana a sus contemporáneos, al tiempo que deja bien en claro que lo que Hierón hizo, lo hizo con una tropa que no se diferenciaba de muchas tropas italianas contemporáneas.

47 Strauss sostiene que estas citas son las que hacen referencia al centro de la segunda parte, que son justamente la enseñanza de la filosofía clásica y la del Antiguo Testamento. La cima de la segunda parte son Jenofonte y el Antiguo Testamento, la cima de la tercera, y del libro como un todo, sería la propia enseñanza de Maquiavelo. Leo Strauss, Thoughts on Machiavelli, University of Chicago Press, Chicago, 1978, pp. 54-84.

48 Maquiavelo, El Príncipe, XIII.

49 Igual que, como veremos, cuando agrega improvisamente a Savonarola en el capítulo VI. El "agregado" suele calificar de manera fundamental lo dicho previamente.

50 Samuel 17:50. Cursivas nuestras. 
armas propias. Si uno presta atención a la cita, descubre que la modificación hace aparecer como armado a quien en realidad no lo estaba tanto.

El verso sigue: "Entonces corrió David y se puso sobre el filisteo; y tomando la espada de él y sacándola de su vaina, lo acabó de matar, y le cortó con ella la cabeza. Y cuando los filisteos vieron a su paladín muerto, huyeron" 51.

Es decir, se puede vencer con las armas de otros. David termina de matar a Goliat apropiándose de las armas que no eran propias. La virtud de David parece entonces asemejarse a la de Borgia, en el sentido de que aquello que demuestra su virtud es la capacidad de apropiarse de las armas de otros y vencer con ellas.

Resulta entonces más importante la temeridad de quien se enfrenta a un enemigo aparentemente superior, y la decisión a la hora de arrebatar las armas a los enemigos en un combate, que la posesión de armas.

Luego de este recorrido, el cierre del argumento es el siguiente: "Concluyo, entonces, diciendo que ningún príncipe está seguro si no tiene armas propias". Entre dos afirmaciones tajantes sobre la importancia de las armas propias, encontramos una sugerencia mucho menos explícita de su importancia relativa.

A continuación, con la aparente intención de apoyar lo que se acaba de decir, Maquiavelo trae una cita de autoridad de Cornelio Tácito (55-120) (aunque no lo menciona): "no hay nada más inseguro e inestable que la fama de potente no basada sobre las propias fuerzas" $"$. La cita es tomada de Anales, XIII, 19, aunque modificada por Maquiavelo. Donde Tácito afirma que "nada de lo mortal es tan inestable e incierto como la fama de poder no nacida de la propia fuerza" ${ }^{53}$, Maquiavelo omite que la afirmación se restringe a "las cosas mortales" y se la hace implícitamente válida para todas las cosas. Una interpretación posible de esta modificación es que aquello que Tácito hace valer para las cosas mortales, Maquiavelo lo hace valer para todas las cosas; en suma, que no hay, para Maquiavelo, sino cosas mortales.

Por otro lado, es preciso notar que el objeto de la afirmación de Tácito no es el poder en sí, sino la fama de poder. En este sentido, se refuerza la importancia de la fama y la reputación acerca del poder, antes que su realidad (o, mejor dicho, que su realidad o verità effettuale está constitutivamente atravesada por la dimensión de la fama o reputación, y esta, por la representación y la apariencia). Asimismo, la mención de Tácito también parece proveernos la indicación de una cita de autoridad fallada, en la medida en que la cita maquiaveliana defiende un argumento distinto en un aspecto fundamental de aquél sostenido por Tácito. Esta referencia a Tácito nos muestra, una vez más, que pese a la apariencia de simplicidad y crudeza del texto maquiaveliano, existen ciertos argumentos que no son expresados de manera completamente abierta $^{54}$. La expansión implícita que produce Maquiavelo de la afirmación de Tácito al hacerla válida para "todas las cosas", convierte la religión en un fenómeno estrictamente político: aun lo inmortal (si hay tal cosa) es inestable e incierto. Los poderes que refieren su legitimidad a un orden inmortal presentado como cierto y estable deben confrontarse con su intrínseca politicidad. Así, la cuestión de las armas nos condujo, por diversas vías, al problema de su relación con la religión.

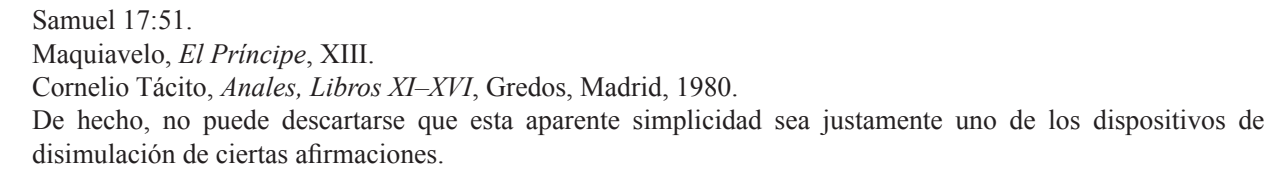




\section{Armas y religión}

Si hasta aquí hemos reparado en varios ejemplos en los que Maquiavelo nos muestra la posibilidad de vencer sin armas propias, no podemos dejar de notar que de diversos modos, estos ejemplos se relacionan con la cuestión del poder de la religión $^{55}$. Como veremos en este apartado, el tratamiento que Maquiavelo hace de la religión católica en El Príncipe, y de la religión de los romanos en los Discursos, parece confirmar esta primera aproximación: la cuestión del fundamento del poder tiene una relación necesaria con la cuestión del poder religioso, y el desafío a esta comprensión de los asuntos humanos resulta fundamental, argumentaremos, para comprender la empresa maquiaveliana en su conjunto. Los capítulos VI y XI de $E l$ Príncipe son, a nuestro juicio, los capítulos fundamentales en la elaboración de la comprensión maquiaveliana de la relación entre armas y religión.

En el capítulo VI, Maquiavelo afirma que "sobre Moisés no se debe discutir, por haber sido mero ejecutor de las cosas que le habían sido ordenadas por Dios", y declara luego que "si consideramos las acciones de Ciro y a los demás fundadores de reinos...aparecerán semejantes a las de Moisés, quien tuvo tan alto preceptor" ${ }^{\text {"56. Es }}$ decir, afirma que no hablará de Moisés, pero luego iguala las acciones de Moisés con aquellos de quienes sí hablará, haciendo de ese tratamiento un tratamiento indirecto de la figura de Moisés mismo.

En el capítulo XI introduce igualmente una falsa exclusión al comienzo:

Son estos principados [los eclesiásticos], por tanto, los únicos seguros y felices. Mas, estando regidos por una razón superior, inalcanzable para una mente humana, los dejaré de lado: elevados y preservados como están por Dios, sería propio de alguien presuntuoso y temerario examinarlos ${ }^{57}$.

Pero inmediatamente introduce a un interlocutor imaginario que lo fuerza, nuevamente, a discutir el tema que había apenas excluido: "empero, alguien podría preguntarme cómo ha llegado en lo temporal a adquirir la Iglesia tanto poder" 58 .

La relevancia de la asociación entre ambos capítulos no se limita al artilugio de la falsa exclusión repetido en ambos casos; esta repetición, sin embargo, llama la atención sobre el hecho de que el texto se abocará al análisis de un tema del que no se debería hablar, y, sin embargo, será analizado por nuestro autor. Podríamos decir que el gesto de afirmar que los asuntos divinos se encuentran en un lugar inalcanzable para el pensamiento, para luego, en los hechos, ser alcanzados por el pensamiento del propio Maquiavelo, constituye un gesto suficientemente elocuente de la voluntad teórica del propio Maquiavelo, y que expresa, sin explicitarla, su opinión sobre los asuntos sagrados.

El capítulo VI se ocupa, según nos informa su título, de Los principados nuevos conquistados con las armas propias y con virtud. Se trata allí de los fundadores de nuevas comunidades políticas: Moisés, Ciro, Rómulo, Teseo. Sin embargo, una

\footnotetext{
55 La única excepción podría ser la de Borgia, quien, sin embargo, era hijo de un Papa, y sucumbe en su aventura política, según Maquiavelo, al equivocarse en la elección de un Papa.

56 Maquiavelo, El Príncipe, VI.

57 Ibid., XI.

58 Ibidem.
} 
inclusión extraña en un capítulo dedicado a este asunto, considero, nos permitirá formular algunos interrogantes acerca de la cuestión de la virtud entendida como conquista del principado con armas propias. Se trata de la referencia a Girolamo Savonarola. Extraña en primer lugar porque Savonarola no es un fundador, y sobre todo, nunca poseyó armas propias; extraña, en segundo lugar, porque la referencia a Savonarola como profeta desarmado que fracasa justamente por carecer de armas, no puede sino recordar al lector a la figura del más célebre de los profetas desarmados quien, por cierto, a diferencia de Savonarola, sí fue fundador de una nueva comunidad política: Cristo (cuya inclusión sería menos llamativa en el contexto de este capítulo). Cristo, a diferencia de Savonarola, no solo no fracasó, sino que puede considerarse con justicia que ha sido un fundador particularmente exitoso ${ }^{59}$. Si recordamos el título del capítulo antes mencionado, podríamos extraer la sugerencia de que si Cristo fundó un principado nuevo, lo adquirió desarmado (y de esto debería encontrarse una explicación), o bien lo adquirió con armas propias y virtud, para lo cual deberíamos expandir la idea de armas propias para comprender su mensaje como un arma aún más poderosa que la posesión de medios para la guerra.

Por otro lado, si en el capítulo VI se afirma que el profeta desarmado no puede triunfar (y esa frase resulta extraña a la luz del destino del profeta desarmado Cristo), en el capítulo XI se hace una nueva afirmación extraña y relacionada: los príncipes de los principados eclesiásticos (es decir, los herederos de Cristo) "tienen estados y no los defienden, tienen súbditos y no los gobiernan" ${ }^{60}$. Se trata de una afirmación inverosímil, especialmente luego de diez capítulos en los que se nos expuso a una enseñanza que hace por lo menos difícil de creer que un principado tal podría existir sin ser ocupado rápidamente por sus vecinos (por no decir que sin gobierno el pueblo tal como Maquiavelo lo describió no podría permanecer unido, mucho menos en paz).

Una primera respuesta a esta cuestión podría ser que se trata de una simple ironía: el papado predica la paz pero tiene ejércitos a su servicio para perseguir fines terrenales ${ }^{61}$. Sin embargo, por cierta que pueda ser esa lectura, consideramos que hay

59 Manent no ve una disonancia en la inclusión de Savonarola en este capítulo. Más bien, afirma que Maquiavelo considera a Savonarola como profeta, y que le confiere a su figura la dignidad de los grandes fundadores. Savonarola, sin embargo, está desarmado y fracasa, mientras que el capítulo está dedicado a quienes están armados y tienen éxito en su empresa. Es decir, Savonarola es utilizado, en principio, como contraejemplo de todos los fundadores gloriosos que están armados y triunfan. Si se hace, como sostenemos, la sugerencia de que Cristo triunfa aun siendo desarmado, ésta no le da a cualquier profeta desarmado la categoría de fundador, menos aún a uno que fracasa a la hora de fundar un reino, y aun en el intento de hacerse con el poder en un orden ya constituido. Véase Manent, Naissances de la politique moderne, pp. 38-40.

60 "Y es que venerables instituciones los asientan en la religión, y es tal su poder y su prestigio que mantienen a sus príncipes en el poder, sea cual fuere su modo de obrar y proceder. Sólo ellos tienen Estados y no los defienden; súbditos, y no los gobiernan. Y los Estados, aun indefensos, no les son arrebatados; a los súbditos, que no estén gobernados, no les preocupa, pues ni piensan ni pueden emanciparse de ellos. Son estos principados, por tanto, los únicos seguros y felices. Mas, estando regidos por una razón superior, inalcanzable para una mente humana, los dejaré de lado: elevados y preservados como están por Dios, sería propio de alguien presuntuoso y temerario examinarlos". Maquiavelo, El Príncipe, XI. Por supuesto, luego de afirmar que sería propio de alguien presuntuoso y temerario examinar el principado eclesiástico, lo examina.

${ }_{61}$ Pocock hace notar el tono irónico de esta descripción: "se nos recuerda la broma de que [el principado eclesiástico] debe ser obra de inspiración divina, puesto que ninguna fundación meramente humana conducida con una imbecilidad tan vil podría durar dos semanas". ("We are reminded of the joke that [the ecclesiastical principality] must be of divine institution since no merely human foundation conducted with such knavish imbecility could last a fortnight"). Sin embargo subsume al principado eclesiástico en una suerte de subcategoría de las monarquías hereditarias en las que la acción del príncipe cuenta aún menos que en ellas. J. G. A. Pocock, 
en juego un problema de mayor espesor en la perplejidad deliberadamente inducida por Maquiavelo en este punto. Hay una verdad en esa expresión de Maquiavelo, y ella describe eso que tentativamente podríamos llamar el aura del poder. La exageración ${ }^{62}$ no hace sino llamar la atención al lector sobre esta dimensión del poder, y poner de manifiesto que existe una obediencia voluntaria cuyo fundamento es la creencia en un poder que no es de este mundo. Muchos hombres ${ }^{63}$ no dejan de prestar reverencia a un poder que evita presentarse como fundado en sí mismo y postula la existencia de una ley superior como principio de su propia legitimidad. Si resulta imposible que un principado se mantenga sin armas, esa imagen, que está fuera de la gramática de la cosa política descripta hasta ese momento, invita a reconsiderar la cuestión de las armas.

Ahora bien, si la imagen de la acumulación lineal de poderío militar (la acumulación de fuerzas) muestra progresivamente sus límites, la imagen opuesta (la de un principado sin armas) no constituye una imagen válida o verosímil sin más, sino que invita a pensar la cuestión del poder en la polaridad que estas dos descripciones inverosímiles (la acumulación bruta de fuerzas, el poderío de quien no protege ni gobierna) instituyen.

En última instancia, la reflexión acerca de la cuestión del poder no puede desembarazarse del problema del origen de la ley y de su legitimidad, sea este humano o superhumano, racional o revelado; o simplemente, efecto de una combinación astuta de fuerza y engaño (que podría ciertamente expresarse, por ejemplo, bajo la fachada de la religión o de una enseñanza de las virtudes morales). Y, al mismo tiempo, si vemos el mismo fenómeno desde el punto de vista del pueblo, podemos ver (como se revela en los pasajes sobre la religión de los romanos), que los hombres, según Maquiavelo, se encuentran dispuestos a obedecer ciertas leyes cuando se aduce que su origen es divino, mientras que las desobedecerían si se mostraran como leyes hechas por hombres para gobernar a otros hombres.

En este sentido, la religión (pero no solo ella) nos muestra que, conociendo la naturaleza de la vida imaginativa de los hombres, resulta posible vencer sin armas propias. Removido el soporte de la autoridad de la trascendencia, no resulta ya posible describir al discurso religioso que refiere a tal autoridad de otra manera que como un engaño. Sin embargo, esta dimensión del engaño, nuevamente, no se restringe al discurso religioso, sino que, como se verá a continuación, describe un problema general de los asuntos políticos.

The Machiavellian Moment: Florentine Political Thought and the Atlantic Republican Tradition, Princeton University Press, Princeton, 2003, pp. 189-194.

62 Sin ser su palabra fundamental sobre el autor, tanto Pocock como Skinner llaman la atención sobre la tendencia de Maquiavelo a la exageración a la hora de presentar ciertos problemas y ciertas historias, aunque la interpretan en un sentido que le asigna un lugar menos decisivo en la estrategia argumental de nuestro autor. Véase ibid., passim; Quentin Skinner, Los fundamentos del pensamiento político moderno, Fondo de Cultura Económica, Mexico, 1987.

63 No solo el pueblo ingenuo, sino incluso quienes, como Baglioni, han transgredido los tabúes más fundamentales que rigen la vida humana. 


\section{El engaño, lo real y lo imaginario}

Probablemente en ningún otro pasaje se exprese con tanta intensidad como en el encabezado del capítulo II, XIII de los Discursos la importancia del engaño como principio de la vida política: "se llega de la baja a la gran fortuna más con el engaño que con la fuerza" ${ }^{4}$. Maquiavelo cita, por ejemplo, a Jenofonte, quien enseña "la necesidad del engaño y cómo [Ciro] con engaño y no con fuerza ocupó su reino" 65 . $\mathrm{Si}$ en el inicio se sostiene simplemente el mayor peso del engaño que la fuerza en el ascenso a una gran fortuna, luego se afirma que este es necesario y suficiente para tal ascenso. Asimismo, se afirma que es "menos vituperable cuanto más encubierto"66 (es decir, cuanto más efectivo). Si esto es así se debe, justamente, a que, al ser encubierto, muchos dejan de percibirlo como tal y, por tanto, no ven motivo para vituperarlo. Esta enseñanza ha sido asignada a Jenofonte, si bien Maquiavelo la distorsiona en cierta medida y la lleva tal vez mucho más allá de su sentido original; la figura del maestro del engaño no queda pues asociada en este pasaje a la figura de Maquiavelo, sino a la de Jenofonte.

La palabra engaño puede resultar poco precisa, puesto que supone aún una relación necesaria y específica entre el orden del aparecer y el orden del ser; es decir, supone que el engaño está dictado por la distancia entre lo que es y lo que aparece, a causa de la manipulación de lo que es por parte de un sujeto para que aparezca como lo desea. Se mantiene, así, la atadura de un orden de lo imaginario, el del engaño, a un orden de lo real que le dicta las condiciones de su verdad o falsedad, y que provee una referencia última respecto de lo que es. Sin embargo, el tratamiento que hace Maquiavelo de la cuestión supone que la imposibilidad de referir el orden del aparecer al del ser no se debe simplemente a la voluntad de uno o varios hombres de manipular lo real para su propia conveniencia (o incluso la de otros), sino a las condiciones mismas de existencia de lo político: si no hay más que apariencias, es porque el conocimiento de las cosas naturales o sobrenaturales no resulta accesible sin más. En este sentido, dice que "las causas de estos prodigios [las señales que anuncian grandes sucesos en una ciudad] toca estudiarlas e interpretarlas a los que tengan conocimientos que nosotros no poseemos, de las cosas naturales y sobrenaturales" $" 67$.

La conjetura inmediatamente posterior parece reforzar el alcance de esta declaración de no saber: "puede ser acaso que, estando el aire poblado de inteligencias, como asegura algún filósofo ${ }^{68}$, dotadas de virtud propia para prever lo futuro, compadecidas de los hombres, les advierten con tales señales para que se preparen a la defensa" ${ }^{\prime 9}$. Si bien el capítulo citado está dedicado a las cosas sobrenaturales

\footnotetext{
64 Maquiavelo, Discursos, II, XIII.

65 Ibidem. Cursivas nuestras.

66 Ibidem.

67 Ibid., I, LVI. La ambigüedad del nosotros no debería ser pasada por alto: no se trata de una declaración de no saber que refiere exclusivamente al propio Maquiavelo, como puede parecer en primera instancia, sino que involucra, al menos también, a sus contemporáneos. No coincidimos con algunas versiones (Gredos, por ejemplo) que prefieren traducir "que yo no poseo", interpretando el plural usado por Maquiavelo en un sentido retórico.

68 Mansfield refiere a Cicerón, De divinatione I, 3064 y a Pomponazzi, Tractatus de inmortalitate animae, 14; Inglese refiere también al De Divinatione de Cicerón; Baussi supone que se trata simplemente de una referencia a una noción de sentido común. Francesco Bausi, I "Discorsi" di Niccolò Machiavelli: genesi e strutture, Sansoni, Firenze, 1985, p. 104.

69 Maquiavelo, Discursos, I, LVI.
} 
que anuncian sucesos políticos, a la hora de hacer la declaración de no saber, esta no refiere simplemente a las cosas sobrenaturales, sino que incluye a las naturales, que no parecían estar en discusión. Asimismo, la referencia a los filósofos, amplía también en otro sentido la declaración de imposibilidad de estudiar e interpretar los prodigios: aun si hubiera inteligencias en el aire que se compadecieran de los hombres y les advirtieran de estas cosas mediante señales, estas requieren interpretación, y la interpretación requiere un conocimiento de las cosas sobrenaturales y naturales que "nosotros no poseemos". En suma, aun si hubiera inteligencias capaces de revelar el futuro, persiste el problema de su exégesis, es decir, el problema de la profecía y de la filosofía en tanto discurso verdadero acerca de las cosas naturales y sobrenaturales. En ausencia de tal referencia, tanto la profecía como la filosofía deben interpretarse en su sentido estrictamente humano en un campo no regido por certezas, puesto que quienes deben elucidar esas señales son hombres no asistidos por un conocimiento cierto de las cosas naturales o sobrenaturales ${ }^{70}$.

El engaño, entonces, no es la manipulación de una realidad cuya entidad e inteligibilidad parecerían estar fuera de duda mediante recursos imaginarios, sino la estructura misma de lo real en tanto que imaginario $^{71}$. Aquello que constituye la realidad política es un juego de apariencias sin referencia a una esencia que le serviría de soporte, sin respaldo de un conocimiento cierto y seguro. Insistamos: el engaño no sería una distorsión de lo que es, sino una comprensión de lo que es, del modo de ser de las cosas políticas.

Si el engaño entonces es, de alguna manera, la naturaleza de lo político, podemos comprender ahora con mayor precisión la idea de que el pasaje de pequeña a gran fortuna se realiza mediante el fraude y el engaño, y no mediante las armas; o, mejor dicho, que las armas están subordinadas a la política (vale recordar solamente el rol fundamental de la relación del pueblo con el orden político para comprender la potencia de la milicia), y que la política se constituye en un orden del engaño.

\section{Conclusión}

Nos propusimos en el inicio de este trabajo poner a prueba la afirmación corriente que sostiene que la posesión de armas propias constituye una de las piezas fundamentales de la enseñanza maquiaveliana. Para ello hemos puesto en juego un trabajo interpretativo del texto maquiaveliano que ha buscado ser minucioso, atento a sus irregularidades o dificultades, que supuso que en esas discordancias del texto se

70 Los problemas que Maquiavelo hace propios y afronta hacen de él un filósofo. En este sentido, nuestra lectura se encuentra más cercana a las de Strauss, e incluso a la de Lefort que a la de Pocock, para quien Maquiavelo resulta más un retórico que un filósofo. Leo Strauss, Thoughts on Machiavelli, passim; Lefort, Le travail de l'œuvre Machiavel; Pocock, The Machiavellian Moment, pp. 58-59. Véase, sobre las interpretaciones straussiana y lefortiana de Maquiavelo respecto de su relación con la filosofía: Bernard Flynn, The Philosophy of Claude Lefort: Interpreting the Political, Northwestern University Press, Evanston, 2005; Marie Gaille, Maquiavelo $y$ la tradición filosófica, Nueva Visión, Buenos Aires, 2011; Claudia Hilb, Leo Strauss: el arte de leer. Una lectura de la interpretación straussiana de Maquiavelo, Hobbes, Locke y Spinoza, Fondo de Cultura Económica, México, 2005; Gérald Sfez, Léo Strauss, lecteur de Machiavel: La modernité du mal, Ellipses, Paris, 2003.

71 Pierre Manent detecta esta incongruencia entre la interpretación realista y la centralidad del engaño: "si el engaño es...el principal recurso de la acción política, es porque él responde a la esencia de la situación politica". ("Si la ruse est...la principale ressource de l'action politique, c'est parce qu'elle répond à l'essence de la situation politique"). Manent, Naissances de la politique moderne, p. 25. 
expresaba un sentido no explícito del texto, y que ha intentado dar cuenta de aquello que pretendía expresarse a través de estos mecanismos ${ }^{72}$. A partir de un trabajo sostenido en estas hipótesis, hemos buscado poner de relieve algunos de los pasajes fundamentales que nos permitan dar cuenta de la cuestión de las armas propias en la obra de Maquiavelo.

Esta lectura, a su vez, nos ha llevado a una revisión de otros aspectos relevantes de la enseñanza maquiaveliana que, según hemos querido mostrar, deben ponerse en juego a la hora de dar una interpretación a esta cuestión: el problema de la apariencia y la escenificación en las relaciones de poder, la relación entre las máximas políticas y las historias que las ilustran (y la cuestión de la lectura y la interpretación del texto maquiaveliano), la relación que Maquiavelo establece entre armas y religión, y la cuestión de la verità effettuale y de las vías de acceso a ella (que lleva implícita la cuestión de la disputa entre filosofía y teología).

Por vía de estas cuestiones, el problema de las armas y de las armas propias se extendió más allá de los que aparecían como sus límites admitidos, revelando algunos aspectos de la compleja relación entre política, religión y filosofía en la obra maquiaveliana. Ellas también resultan ser, en cierto modo, si nuestra interpretación no es inadecuada, armas, y es en el terreno en que estas son efectivas que la propia obra maquiaveliana hace una de sus intervenciones fundamentales.

\section{Referencias bibliográficas}

Bausi, Francesco, I "Discorsi” di Niccolò Machiavelli: genesi e strutture, Sansoni, Firenze, 1985.

Butterfield, Herbert, The Statecraft of Machiavelli, Collier, New York, 1962.

Dotti, Ugo, Niccolò Machiavelli: la fenomenologia del potere, Feltrinelli, Milano, 1979.

Flynn, Bernard, The Philosophy of Claude Lefort: Interpreting the Political, Northwestern University Press, Evanston, 2005.

Gaille, Marie, Maquiavelo y la tradición filosófica, Nueva Visión, Buenos Aires, 2011.

Gilbert, Felix, Machiavelli e il suo tempo, Il Mulino, Bologna, 1964.

—, "On Machiavelli's Idea of Virtu": Renaissance News, vol. IV, n. ${ }^{\circ} 4$ (1951), pp. 53-55.

Hilb, Claudia, Leo Strauss: el arte de leer. Una lectura de la interpretación straussiana de Maquiavelo, Hobbes, Locke y Spinoza, Fondo de Cultura Económica, México, 2005.

Lefort, Claude, Le travail de l'auvre Machiavel, Gallimard, Paris, 1972.

Manent, Pierre, Naissances de la politique moderne: Machiavel, Hobbes, Rousseau, Payot, Paris, 1977.

Mansfield, Harvey C., Machiavelli's virtue, University of Chicago Press, Chicago, 1996.

Maquiavelo, Nicolás, El Príncipe, Alianza, Madrid, 1995.

-, Obras seleccionadas, Gredos, Madrid, 2011.

Merleau-Ponty, Maurice, "Note sur Machiavel": Les Temps Modernes V, n. ${ }^{\circ} 48$ (1949), pp. 557-593.

Mindle, Grant B., "Machiavelli's Realism": The Review of Politics, vol. 47, n. 2 (1985), pp. 212-230.

Olschki, Leonardo, Machiavelli the Scientist, Gillick Press, Berkeley, 1945.

72 Debemos mencionar la influencia de los trabajos de Leo Strauss en nuestra manera de afrontar la lectura e interpretación del texto maquiaveliano, aunque no desprendamos de ella las mismas conclusiones. Véase Strauss, Thoughts on Machiavelli, pp. 174-299. 
Orwin, Clifford, "Machiavelli's Unchristian Charity": The American Political Science Review, vol. 72, n. ${ }^{\circ} 4$ (1978), pp. 1217-1228.

Pocock, J. G. A., The Machiavellian Moment: Florentine Political Thought and the Atlantic Republican Tradition, Princeton University Press, Princeton, 2003.

Rinesi, Eduardo, Politica y tragedia: Hamlet entre Hobbes y Maquiavelo, Ediciones Colihue, Buenos Aires, 2003.

Sfez, Gérald, Léo Strauss, lecteur de Machiavel: La modernité du mal, Ellipses, Paris, 2003.

Skinner, Quentin, The Foundations of Modern Political Thought, Cambridge University Press, Cambridge, 1978.

- Los fundamentos del pensamiento político moderno, Fondo de Cultura Económica, México, 1987.

Strauss, Leo, Thoughts on Machiavelli, University of Chicago Press, Chicago, 1978.

Tácito, Cornelio, Anales, Libros XI-XVI, Gredos, Madrid, 1980.

Tarcov, Nathan, "Machiavelli in The Prince", en Thomas L. Pangle y J. Harvey Lomax (eds.), Political Philosophy Cross-Examined: Perennial Challenges to the Philosophic Life, Palgrave Macmillan, New York, 2013, pp. 101-118.

Vissing, Lars, Machiavel et la politique de l'apparence, Presses Universitaires de France, Paris, 1986. 